OPEN ACCESS

Edited by:

Merce Correa,

Jaume I University, Spain

Reviewed by:

María José Sánchez-Catalán,

Universitat de València, Spain

Mario Rivera-Meza,

Universidad de Chile, Chile

${ }^{*}$ Correspondence:

Paolo Enrico

enrico@uniss.it

Received: 25 January 2017 Accepted: 09 May 2017

Published: 30 May 2017

Citation:

Enrico P and Diana M (2017) On

the Accuracy of In Vivo Ethanol and Acetaldehyde Monitoring, a Key Tile in the Puzzle of Acetaldehyde as a Neuroactive Agent.

Front. Behav. Neurosci. 11:97. doi: 10.3389/fnbeh.2017.00097

\section{On the Accuracy of In Vivo Ethanol and Acetaldehyde Monitoring, a Key Tile in the Puzzle of Acetaldehyde as a Neuroactive Agent}

\author{
Paolo Enrico ${ }^{* *}$ and Marco Diana ${ }^{2}$ \\ 'Department of Biomedical Sciences, University of Sassari, Sassari, Italy, ' 'G. Minardi' Cognitive Neuroscience Laboratory, \\ Department of Chemistry and Pharmacy, University of Sassari, Sassari, Italy
}

Over the last 20 years researchers have explored the postulated role of acetaldehyde (ACD) as a mediator of some of the actions of ethanol (EtOH) in the central nervous system (CNS). However, efforts have been hampered mainly by the difficulty of directly measuring in vivo $\mathrm{EtOH}$ and $\mathrm{ACD}$ levels in the CNS and thus, our knowledge is based on indirect evidences. Although technically challenging, the development of reliable methods for in vivo measurement of $\mathrm{ACD}$ and $\mathrm{EtOH}$ is of paramount importance to solve the "puzzle of acetaldehyde as a neuroactive agent." In this short review we discuss the recent advances on brain $\mathrm{EtOH}$ pharmacokinetic and state-of-theart available techniques that could be used for in vivo detect $\mathrm{EtOH}$ and $\mathrm{ACD}$ both non-invasively (magnetic resonance spectroscopy), and invasively (microdialysis and biosensors). Among the different in vivo sampling techniques described, particular emphasis is paid to the field of enzyme-based amperometric biosensors. Biosensors have gained much attention in recent years for their ability to online monitor biological signals in vivo, and several micro- and nano-structured devices have been successfully used for in vivo studies. Owing to their high temporal and spatial resolution, biosensors could provide the adequate technology for studying in vivo EtOH pharmacokinetic.

Keywords: ethanol, acetaldehyde, magnetic resonance spectroscopy, microdialysis, biosensors

\section{INTRODUCTION}

Acetaldehyde (ACD) is a naturally occurring compound, found in several fruits and vegetables as well as in tobacco smoke and fermented alcoholic beverages (Cao et al., 2007).

In the last decades many attempts have been made to quantify brain EtOH and ACD, in order to correlate their concentrations with behavior (Correa et al., 2012; Israel et al., 2015). So far this line of research has yielded conflicting results, mostly due to discrepancy and controversy with quantitative measures of brain $\mathrm{EtOH}$ and $\mathrm{ACD}$.

In this brief review we offer an overview of the recent advances on brain EtOH pharmacokinetic and discuss the state-of-the-art of available techniques for in vivo EtOH and ACD study. 


\section{EtOH METABOLISM IN THE BRAIN}

Since EtOH readily enters the brain, in situ synthesis has been long postulated as a plausible source of brain ACD (Cohen et al., 1980). It is now demonstrated that the brain tissue contains all of the main EtOH metabolizing enzymes: alcohol dehydrogenase (ADH), cytochrome P450 2E1 (CYP2E1), and catalase; however, their relative role in metabolizing $\mathrm{EtOH}$ into ACD is still debated.

Alcohol dehydrogenase is a zinc-containing enzyme localized in the cytosol, it has broad substrate specificity (many primary or secondary alcohols) and is found in highest amount in the liver. However, since ADH is not uniformly expressed in the brain tissue, its real contribution to local ACD levels in discrete brain areas could have been underestimated and may deserve more detailed evaluation (Bühler et al., 1983; Kerr et al., 1989; Mori et al., 2000).

Cytochrome P450s are a family of heme enzymes mainly located in the endoplasmic reticulum and in mitochondria. CYP2E1 is the P450 family with the highest activity for oxidizing $\mathrm{EtOH}$ to ACD, and is widely expressed in the human and rodent brain (Tindberg and Ingelman-Sundberg, 1996; SánchezCatalán et al., 2008; Ferguson and Tyndale, 2011). CYP2E1 has been shown to metabolize EtOH in both neurons and astrocytes at a rate of $0.00051 \mu \mathrm{mol} / \mathrm{min} / \mathrm{g}$, and CYP2E1 pharmacological inhibition significantly reduces ACD formation in rat brain homogenates incubated with $\mathrm{EtOH}$ (Hansson et al., 1990; Gill et al., 1992; Warner and Gustafsson, 1994; Zimatkin et al., 2006). Further, reduced ACD brain levels have been shown in transgenic KO CYP2E1 mice after incubation with $\mathrm{EtOH}$, relative to their wild-type counterparts (Ziegler et al., 2006). CYP2E1 activity has been accounted for a $20 \%$ fraction of brain EtOH oxidation, and it may represents a major adaptive response to chronic EtOH consumption as shown in a recent in vivo study on $\mathrm{EtOH}$-induced locomotion (Hansson et al., 1990; Heit et al., 2013; Ledesma et al., 2014). Further, in vitro evidences in KO CYP2E1, acatalasemic and double mutants (KO CYP2E1 and acatalasemic) mice, suggest that CYP2E1 function may be linked to catalasemediated $\mathrm{EtOH}$ oxidation by increasing the availability of $\mathrm{H}_{2} \mathrm{O}_{2}$ (Halliwell, 2006; Zimatkin et al., 2006; Deng and Ra, 2008).

Catalase, a heme containing enzyme, is found in the peroxisomal fraction of the cell and can oxidize $\mathrm{EtOH}$ as shown in reaction 1.

$$
\text { (1) } \mathrm{CH}_{3} \mathrm{CH}_{2} \mathrm{OH}+\mathrm{H}_{2} \mathrm{O}_{2} \rightarrow \mathrm{CH}_{3} \mathrm{CHO}+2 \mathrm{H}_{2} \mathrm{O}
$$

Recent results also show that 3-amino-1,2,4-triazole (3AT) administration impair the acquisition of operant EtOH selfadministration in the rat (Peana et al., 2015). However, 3AT has been shown to cause a non-specific effects on behavior and therefore other procedures have been used to inhibit catalasemediated ACD formation (Rotzinger et al., 1994; Tampier et al., 1995).

A valuable method for in vivo studying the involvement of catalase in brain ACD formation is based on the use of lentiviral vectors coding for an anticatalase shRNA (RNAi precursor), which allows for efficient (up to 75\%) inhibition of catalase activity (Karahanian et al., 2011). This technique appears also of particular interest because by allowing localized inhibition of catalase activity, it may be used to precisely pinpoint those brain areas involved in the psychopharmacological effects of EtOH (Israel et al., 2015). In fact, it has been shown that administration of an anticalatase vector into the ventral tegmental area (area which plays a key role in the neurobiological basis of addiction, VTA), significantly reduced EtOH consumption and $\mathrm{EtOH}$ stimulated dopamine release in its projection fields (in particular the nucleus accumbens shell) (Karahanian et al., 2011; Israel et al., 2012; Quintanilla et al., 2012). Another study show that anticatalase vectors administration in the VTA can efficiently inhibit $\mathrm{EtOH}$ intake following deprivation (Tampier et al., 2013).

\section{IN VIVO ETOH AND ACD DETECTION: NON-INVASIVE APPROACHES}

\section{Magnetic Resonance Spectroscopy}

Magnetic resonance spectroscopy (MRS) is a non-invasive analytical technique used to provide a measure of in vivo brain biochemistry (Soares and Law, 2009; Strózik-Kotlorz, 2014; Buonocore and Maddock, 2015). In vivo MRS can be performed with common clinical magnetic resonance imaging equipments and since EtOH methyl protons can be detected (Sammi et al., 2000), MRS has been largely used to measure in vivo brain $\mathrm{EtOH}$ levels in both humans and laboratory animals (Hanstock et al., 1990; Kaufman et al., 1994; Rooney et al., 2000; Zahr et al., 2010). However, magnetic transfer evidences have clearly shown the in vivo presence of a free, observable EtOH pool and a membrane-associated $\mathrm{EtOH}$ pool that escapes direct detection (Fein and Meyerhoff, 2000; Nagel and Kroenke, 2008). Therefore, since a (possibly significant) fraction of brain EtOH content cannot be measured by MRS, this technique must be considered only for qualitative measurements.

Ethanol oxidative metabolism has been studied with MRS, after ${ }^{13} \mathrm{C}$-labeled EtOH administration (Xiang and Shen, 2011; Wang et al., 2013a,b).The results show that ${ }^{13} \mathrm{C}$ nuclei from ${ }^{13} \mathrm{C}$-labeled $\mathrm{EtOH}$ are incorporated into multiple metabolites including glutamate, glutamine, and aspartate, but no significant conversion of EtOH into ACD in the brain could be evidenced.

Despite the low sensitivity and temporal resolution, MRS still provides an opportunity for in vivo qualitative study of the effects of EtOH in the brain (Nagel and Kroenke, 2008; Niciu and Mason, 2014). MRS is fundamental for human studies allowing the dynamic evaluation of $\mathrm{EtOH}$ effects, and providing an important framework for comparing experimental results in humans and animal models (Cifuentes Castro et al., 2014). Further, since magnetic resonance images can be obtained concurrently with spectroscopic data, MRS also provides valuable structural informations (Alger, 2010; Befroy and Shulman, 2011). 


\section{IN VIVO ETOH AND ACD DETECTION: INVASIVE APPROACHES}

\section{Microdialysis}

Microdialysis is de facto the gold-standard in vivo sampling technique for the central nervous system (CNS), allowing the analysis of several molecules in cerebro spinal fluid (CSF) based on their diffusion across a semi-permeable membrane (Chefer et al., 2009; Kennedy, 2013). Despite its popularity, microdialysis is not free of limitations (Westerink, 1995), some of which are particularly relevant for $\mathrm{EtOH}$ and $\mathrm{ACD}$ in vivo measurement. In particular, due to low probe recovery, the concentrations of substances in the dialysate only partially reflect true tissue concentrations and thus, analytes present at very low concentrations are difficult to detect. This issue could be also worsened by the fact that some compounds may be adsorbed by the dialysis membrane further decreasing probe recovery (Buttler et al., 1996). It is well-known that microdialysis has poor time resolution and therefore is not suitable for studying events that change in short time intervals. Another problem is the effect of tissue damage secondary to probe implantation; although microdialysis probes have been miniaturized in time, alterations in tissue metabolism cannot be neglected (Borland et al., 2005; Carson et al., 2015).

Despite all technical shortcomings, the advantages of using microdialysis for in vivo monitoring of brain neurochemistry are clear. Microdialysis is a well-known and widely reproduced technique, sampling can be performed on freely moving subjects, and long-term studies can be carried out with minimal influence on the brain tissue physiology (Westerink, 1995; Chefer et al., 2009; Kennedy, 2013). On these bases, several authors used brain microdialysis to study EtOH and ACD in vivo (Yoshimoto and Komura, 1993; Jamal et al., 2003, 2007, 2015). However, this approach yielded only limited results, mostly due to the various technical and analytical issues which specifically impair the usefulness of microdialysis for $\mathrm{EtOH}$ and (especially) ACD in vivo monitoring.

\section{High Performance Liquid Chromatography (HPLC)}

High performance liquid chromatography (HPLC)-based analytical methods are largely employed in microdialysis studies (Cheng et al., 2009; Guihen and O'Connor, 2009). With regard to EtOH and ACD determination HPLC-based methods appear particularly suitable, since samples are not heated during analysis and thus heat sensitive or volatile compounds (such as EtOH and ACD) can be efficiently separated. Several protocols for EtOH analysis with HPLC have been developed using flame ionization detection (Yarita et al., 2002), ultraviolet detection after conversion to acetaldehyde-phenylhydrazone (Pellegrino et al., 1999), indirect photometric detection (Takeuchi et al., 1988), and enzymatic assay (Kristoffersen and Smith-Kielland, 2005; Peris et al., 2006). An optimized HPLC-based protocol for ACD determination in biological samples after derivatization with dinitrophenylhydrazine (Vogel et al., 2000) and diode array detector is also available (Guan et al., 2011).

\section{Gas Chromatography (GC)}

Gas chromatography (GC) is an efficient analytical technique for separating volatile species in complex samples, and several GCbased protocols have been developed for the detection of EtOH and ACD in biological matrices.

Several detector types can be used in conjunction with GC for $\mathrm{EtOH}$ and $\mathrm{ACD}$ detection; the most efficient protocols available have been developed mainly using mass spectrometry (GC-MS) (Heit et al., 2016) or flame ionization (GC-FID) (Chun et al., 2016), alone or in combination (Tiscione et al., 2011).

Gas chromatography with headspace extraction and mass spectrometry or flame ionization detection is the most reliable and sensitive technique available for EtOH and ACD detection in microdialysates (Xiao et al., 2014; Heit et al., 2016). Indeed, owing to their robustness and reliability, GC-based EtOH analysis are the gold standard technique for blood alcohol concentration measurement in forensic and toxicological laboratories (Cordell et al., 2013; Xiao et al., 2014; Goullé and Guerbet, 2015).

\section{Fluorimetry}

A new fluorimetry-based analytical method for EtOH and ACD has been recently published (Zachut et al., 2016). Although not specifically developed for EtOH and ACD detection in brain dialysates, this technique appears quite compatible with microdialysis; in particular: small sample volume, no sample pre-processing, simple methodology, relatively inexpensive laboratory equipment. Further, the limits of detection of the technique are reported to be comparable with the performance of GC methods.

\section{Biosensors}

A biosensor can be defined as "a self-contained analytical device that combines a biological component with a physicochemical device for the detection of an analyte of biological importance" (Hasan et al., 2014). Biosensors typically consist of two key components: (1) a biological recognition element to detect the analyte; (2) a transducer to convert the biological response into a convenient output signal.

Among the different devices available, amperometric enzymebased biosensors (AEBs) are increasingly employed in in vivo brain monitoring (Thévenot et al., 2001; Weltin et al., 2016). In fact, miniature (active surface $-1 \mathrm{~mm}$, diameter - $150 \mu \mathrm{m}$ ) AEBs implantation induces reduced tissue damage, allows for realtime monitoring, with high sensitivity and specificity for analytes which cannot be studied with microdialysis (Timmerman and Westerink, 1997; Sirca et al., 2014). Another important feature of biosensors is the possibility of associating the implanted device to a telemetric system, allowing experiments in freely moving subjects (Olivo et al., 2011).

Amperometric enzyme-based biosensors are mainly based on enzymes that belong to two classes: oxidases and dehydrogenases; in their most common implementation the enzyme is linked on the transducer surface and the output signal is generated by measuring the electroactive by-products of enzymatic reaction.

In recent years several AEBs for EtOH detection have been developed, based on both alcohol oxidase (AOx) or dehydrogenase $(\mathrm{ADH})$. 
Alcohol oxidase catalyzes the oxidation of aliphatic, low molecular weight alcohols to their respective aldehydes using molecular oxygen $\left(\mathrm{O}_{2}\right)$ as the electron acceptor and flavinadenine dinucleotide (FAD) as cofactor (reactions 2 and 3).

(2) $\mathrm{R}-\mathrm{CH}_{2} \mathrm{OH}+\mathrm{AOx} / \mathrm{FAD} \rightarrow \mathrm{R}-\mathrm{CHO}+\mathrm{AOx} / \mathrm{FADH}_{2}$

$$
\text { (3) } \mathrm{AOx} / \mathrm{FADH}_{2}+\mathrm{O}_{2} \rightarrow \mathrm{AOx} / \mathrm{FAD}+\mathrm{H}_{2} \mathrm{O}_{2}
$$

$$
\text { (4) } \mathrm{H}_{2} \mathrm{O}_{2} \rightarrow \mathrm{O}_{2}+2 \mathrm{H}^{+}+2 \mathrm{e}^{-}
$$

The hydrogen peroxide produced by reaction 3 can be directly detected at the transducer surface of AOx-based AEBs (reaction 4). However, the high anodic potential needed to oxidize $\mathrm{H}_{2} \mathrm{O}_{2}$ poses a problem of Faradaic interference due to the presence of other compounds (such as ascorbic acid and uric acid) physiologically present in high concentrations in the CSF, which are also oxidized at the same potential (Belluzo et al., 2008). The use of a bi-enzyme AEB is a common way to circumvent this problem. In fact, by coupling a peroxidase [usually horseradish peroxidase (HRP)] to AOx it is possible to indirectly monitor EtOH-derived $\mathrm{H}_{2} \mathrm{O}_{2}$ at low working potentials reducing interfering signals (Vijayakumar et al., 1996; Azevedo et al., 2005).

$$
\text { (5) } \mathrm{H}_{2} \mathrm{O}_{2}+2 \mathrm{H}^{+}+\mathrm{HRP}^{-} \rightarrow 2 \mathrm{H}_{2} \mathrm{O}+\mathrm{HRP}^{+}
$$

The $\mathrm{HRP}^{+} / \mathrm{HRP}^{-}$redox couple (reaction 5) is used as the sensing scheme at the transducer surface of AOx/HRP-based AEBs.

Alcohol dehydrogenase catalyzes the reversible oxidation of primary aliphatic and aromatic alcohols using nicotinamideadenine dinucleotide (NAD) as cofactor (reaction 6).

(6) $\mathrm{R}-\mathrm{CH}_{2} \mathrm{OH}+\mathrm{ADH} / \mathrm{NAD}^{+} \rightarrow \mathrm{R}-\mathrm{CHO}+\mathrm{ADH} / \mathrm{NADH}+\mathrm{H}^{+}$

$$
\text { (7) } \mathrm{NADH} \rightarrow \mathrm{NAD}^{+}+\mathrm{H}^{+}+2 \mathrm{e}^{-}
$$

The most common way to monitor an ADH-catalyzed reaction is by using the $\mathrm{NAD}^{+} / \mathrm{NADH}$ redox couple (reaction 7) as the sensing scheme at the transducer surface of ADH-based AEBs (Lorenzo et al., 1998).

Acetaldehyde biosensors developed so far are based on ALDH, which catalyzes the oxidation of biogenic and xenobiotic aldehydes (including ACD) into acetate using NAD as cofactor (reaction 8).

(8) $\mathrm{R}-\mathrm{CHO}+\mathrm{ALDH} / \mathrm{NAD}^{+} \rightarrow \mathrm{R}-\mathrm{COOH}+\mathrm{ALDH} / \mathrm{NADH}+\mathrm{H}^{+}$

$$
\text { (9) } \mathrm{NADH} \rightarrow \mathrm{NAD}+\mathrm{H}^{+}+2 \mathrm{e}^{-}
$$

The ALDH-catalyzed reaction is monitored by using the NAD+/NADH redox couple (reaction 9) as the sensing scheme at the transducer surface of ALDH-based AEBs (Lorenzo et al., 1998).

Acetaldehyde biosensors have been mostly developed for toxicological and industrial purposes and therefore their biological applicative potential is much less characterized, when compared with EtOH AEBs. However the available evidence show that these devices can efficiently detect ACD in the $\mu \mathrm{M}$ range in vitro, with high time resolution and substrate specificity (Noguer and Marty, 1997; Noguer et al., 2001; Avramescu et al., 2002; Yao and Handa, 2003; Ghica et al., 2007).

Although the development of an adequate biosensor technology for in vivo EtOH and ACD detection is still in its infancy, the available evidence clearly show that this approach holds tremendous technological potential. In fact the prototypical properties of biosensors including high spatial and temporal resolution together with high sensitivity and specificity, render these devices the best candidates for in vivo accurate $\mathrm{EtOH}$ and ACD detection.

Several AEBs for in vivo EtOH determination are already commercially available; however since in vivo biosensors use is not deprived of drawbacks, the fundamentals of this technology are to be well-understood in order to obtain reproducible results (Vigneshvar et al., 2015; Weltin et al., 2016). In particular, the interactions of the implanted AEB with the biological environment may severely affect its bioanalytical performances via metabolic biofouling, electrode passivation, or biodegradation. Metabolic biofouling is probably the most important problem being able to quickly alter sensitivity, limit of detection, and linear response of the implanted device (Gifford et al., 2006; Kotanen et al., 2012). Unfortunately, biocompatibility-based issues cannot be easily circumvented and adequate pre- and post-calibration procedures are needed in order to properly evaluate in vivo AEBs measurements (Wilson and Gifford, 2004; Wahono et al., 2012). However it is expected that the forthcoming generation of biosensors, either based on nanoscale or polymeric materials, will greatly help reducing biocompatibility issues (Nichols et al., 2013; Weltin et al., 2014; Saxena and Das, 2016).

\section{CONCLUSION}

The many attempts to quantify ACD in the brain have yielded conflicting results, mainly because of the inadequacy of the available analytical techniques. Thus, it is clear that in order to solve the puzzle of ACD as a neuroactive agent we need to use adequate analytical tools, fostering their improvement, while discarding the most problematic approaches.

Spectroscopic techniques have proved to be useful for studying in vivo brain EtOH kinetics, in both humans and experimental animals, but ACD measurement remains outside MRS analytical scope. Nevertheless, owing to its absolute non-invasive nature MRS provides a great opportunity for in vivo qualitative study of the effects of $\mathrm{EtOH}$ in the intact brain.

Brain microdialysis is a well-known sampling technique for in vivo applications. However, it is now clear that many of the features that made microdialysis so successful for in vivo monitoring of several neurochemicals, are of limited use when coming to in vivo $\mathrm{EtOH}$ and (especially) $\mathrm{ACD}$ analysis. Its invasiveness together with the low temporal resolution, and the necessity of complex analytical procedures, represent the most important problems. 
Biosensors are the emerging tool for the preclinical in vivo study of neurochemistry. When compared to microdialysis the main advantages of AEBs are represented by their reduced invasiveness, high time resolution, and the possibility to detect analytes which cannot be studied with microdialysis. In the case of EtOH monitoring, AOX-based AEBs have proved to be capable of in vitro and in vivo detecting concentrations of $\mathrm{EtOH}$ in the $\mu \mathrm{M}$ range. ALDH-based ACD AEBs have not been applied for in vivo ACD detection yet, however in vitro data strongly suggest that these devices may represent

\section{REFERENCES}

Alger, J. R. (2010). Quantitative proton magnetic resonance spectroscopy and spectroscopic imaging of the brain: a didactic review. Top. Magn. Reson. Imaging 21, 115-128. doi: 10.1097/RMR.0b013e31821e568f

Avramescu, A., Noguer, T., Avramescu, M., and Marty, J.-L. (2002). Screen-printed biosensors for the control of wine quality based on lactate and acetaldehyde determination. Anal. Chim. Acta 458, 203-213. doi: 10.1016/S0003-2670(01) 01580-X

Azevedo, A. M., Prazeres, D. M. F., Cabral, J. M. S., and Fonseca, L. P. (2005). Ethanol biosensors based on alcohol oxidase. Biosens. Bioelectron. 21, 235-247. doi: $10.1016 /$ j.bios.2004.09.030

Befroy, D. E., and Shulman, G. I. (2011). Magnetic resonance spectroscopy studies of human metabolism. Diabetes Metab. Res. Rev. 60, 1361-1369. doi: 10.2337/ db09-0916

Belluzo, M. S., Ribone, M. E., and Lagier, C. M. (2008). Assembling amperometric biosensors for clinical diagnostics. Sensors 8, 1366-1399. doi: 10.3390/s8031366

Borland, L. M., Shi, G., Yang, H., and Michael, A. C. (2005). Voltammetric study of extracellular dopamine near microdialysis probes acutely implanted in the striatum of the anesthetized rat. J. Neurosci. Methods 146, 149-158. doi: 10.1016/j.jneumeth.2005.02.002

Bühler, R., Pestalozzi, D., Hess, M., and Von Wartburg, J. P. (1983). Immunohistochemical localization of alcohol dehydrogenase in human kidney, endocrine organs and brain. Pharmacol. Biochem. Behav. 18(Suppl. 1), 55-59. doi: 10.1016/0091-3057(83)90147-8

Buonocore, M. H., and Maddock, R. J. (2015). Magnetic resonance spectroscopy of the brain: a review of physical principles and technical methods. Rev. Neurosci. 26, 609-632. doi: 10.1515/revneuro-2015-0010

Buttler, T., Nilsson, C., Gorton, L., Marko-Varga, G., and Laurell, T. (1996). Membrane characterisation and performance of microdialysis probes intended for use as bioprocess sampling units. J. Chromatogr. A 725, 41-56. doi: 10.1016/ 0021-9673(95)01120-X

Cao, J., Belluzzi, J. D., Loughlin, S. E., Keyler, D. E., Pentel, P. R., and Leslie, F. M. (2007). Acetaldehyde, a major constituent of tobacco smoke, enhances behavioral, endocrine, and neuronal responses to nicotine in adolescent and adult rats. Neuropsychopharmacology 32, 2025-2035. doi: 10.1038/sj.npp. 1301327

Carson, B. P., McCormack, W. G., Conway, C., Cooke, J., Saunders, J., O'Connor, W. T., et al. (2015). An in vivo microdialysis characterization of the transient changes in the interstitial dialysate concentration of metabolites and cytokines in human skeletal muscle in response to insertion of a microdialysis probe. Cytokine 71, 327-333. doi: 10.1016/j.cyto.2014.10.022

Chefer, V. I., Thompson, A. C., Zapata, A., and Shippenberg, T. S. (2009). Overview of brain microdialysis. Curr. Protoc. Neurosci. Chapter 7:Unit7.1. doi: 10.1002/ 0471142301.ns0701s47

Cheng, G.-W., Hsu, K.-C., Lee, C.-F., Wu, H.-L., and Huang, Y.-L. (2009). Online microdialysis coupled with liquid chromatography for biomedical analysis. J. Chromatogr. Sci. 47, 624-630. doi: 10.1093/chromsci/47.8.624

Chun, H.-J., Poklis, J. L., Poklis, A., and Wolf, C. E. (2016). Development and validation of a method for alcohol analysis in brain tissue by headspace gas chromatography with flame ionization detector. J. Anal. Toxicol. 40, 653-658. doi: 10.1093/jat/bkw075

Cifuentes Castro, V. H., López Valenzuela, C. L., Salazar Sánchez, J. C., Peña, K. P., López Pérez, S. J., Ibarra, J. O., et al. (2014). An update of the classical the most promising opportunity for in vivo brain ACD detection.

\section{AUTHOR CONTRIBUTIONS}

PE: performed literature analysis and data collection, wrote manuscript and acted as corresponding author. MD: supervised development of work, helped in data interpretation and manuscript evaluation and editing.

and novel methods used for measuring fast neurotransmitters during normal and brain altered function. Curr. Neuropharmacol. 12, 490-508. doi: 10.2174/ 1570159X13666141223223657

Cohen, G., Sinet, P. M., and Heikkila, R. (1980). Ethanol oxidation by rat brain in vivo. Alcohol. Clin. Exp. Res. 4, 366-370. doi: 10.1111/j.1530-0277.1980. tb04833.x

Cordell, R. L., Pandya, H., Hubbard, M., Turner, M. A., and Monks, P. S. (2013). GC-MS analysis of ethanol and other volatile compounds in micro-volume blood samples-quantifying neonatal exposure. Anal. Bioanal. Chem. 405, 4139-4147. doi: 10.1007/s00216-013-6809-1

Correa, M., Salamone, J. D., Segovia, K. N., Pardo, M., Longoni R., Spina L., et al. (2012). Piecing together the puzzle of acetaldehyde as a neuroactive agent. Neurosci. Biobehav. Rev. 36, 404-430. doi: 10.1016/j.neubiorev.2011.07.009

Deng, X.-S., and Ra, D. (2008). Putative role of brain acetaldehyde in ethanol addiction. Curr. Drug Abuse Rev. 1, 3-8. doi: 10.2174/1874473710801010003

Fein, G., and Meyerhoff, D. J. (2000). Ethanol in human brain by magnetic resonance spectroscopy: correlation with blood and breath levels, relaxation, and magnetization transfer. Alcohol. Clin. Exp. Res. 24, 1227-1235. doi: 10.1111/ j.1530-0277.2000.tb02088.x

Ferguson, C. S., and Tyndale, R. F. (2011). Cytochrome P450 enzymes in the brain: emerging evidence of biological significance. Trends Pharmacol. Sci. 32, 708-714. doi: 10.1016/j.tips.2011.08.005

Ghica, M. E., Pauliukaite, R., Marchand, N., Devic, E., and Brett, C. M. A. (2007). An improved biosensor for acetaldehyde determination using a bienzymatic strategy at poly(neutral red) modified carbon film electrodes. Anal. Chim. Acta 591, 80-86. doi: 10.1016/j.aca.2007.03.047

Gifford, R., Kehoe, J. J., Barnes, S. L., Kornilayev, B. A., Alterman, M. A., and Wilson, G. S. (2006). Protein interactions with subcutaneously implanted biosensors. Biomaterials 27, 2587-2598. doi: 10.1016/j.biomaterials.2005. 11.033

Gill, K., Menez, J. F., Lucas, D., and Deitrich, R. A. (1992). Enzymatic production of acetaldehyde from ethanol in rat brain tissue. Alcohol. Clin. Exp. Res. 16, 910-915. doi: 10.1111/j.1530-0277.1992.tb01892.x

Goullé, J.-P., and Guerbet, M. (2015). [Pharmacokinetics, metabolism, and analytical methods of ethanol]. Ann. Pharm. Fr. 73, 313-322. doi: 10.1016/j. pharma.2015.03.003

Guan, X., Rubin, E., and Anni, H. (2011). An optimized method for the measurement of acetaldehyde by high-performance liquid chromatography. Alcohol. Clin. Exp. Res. 36, 398-405. doi: 10.1111/j.1530-0277.2011.01612.x

Guihen, E., and O'Connor, W. T. (2009). Current separation and detection methods in microdialysis the drive towards sensitivity and speed. Electrophoresis 30, 2062-2075. doi: 10.1002/elps.200900039

Halliwell, B. (2006). Oxidative stress and neurodegeneration: where are we now? J. Neurochem. 97, 1634-1658. doi: 10.1111/j.1471-4159.2006.03907.x

Hansson, T., Tindberg, N., Ingelman-Sundberg, M., and Köhler, C. (1990). Regional distribution of ethanol-inducible cytochrome P450 IIE1 in the rat central nervous system. Neuroscience 34, 451-463. doi: 10.1016/0306-4522(90) 90154-V

Hanstock, C. C., Rothman, D. L., Shulman, R. G., Novotny, E. J., Petroff, O. A., and Prichard, J. W. (1990). Measurement of ethanol in the human brain using NMR spectroscopy. J. Stud. Alcohol 51, 104-107. doi: 10.15288/jsa.1990.51.104

Hasan, A., Nurunnabi, M., Morshed, M., Paul, A., Polini, A., Kuila, T., et al. (2014). Recent advances in application of biosensors in tissue engineering. Biomed Res. Int. 2014:307519. doi: 10.1155/2014/307519 
Heit, C., Dong, H., Chen, Y., Thompson, D. C., Deitrich, R. A., and Vasiliou, V. K. (2013). "The role of CYP2E1 in alcohol metabolism and sensitivity in the central nervous system," in Cytochrome P450 2E1: Its Role in Disease and Drug Metabolism Subcellular Biochemistry, ed. A. Dey (Dordrecht: Springer), 235-247. doi: 10.1007/978-94-007-5881-0_8

Heit, C., Eriksson, P., Thompson, D. C., Charkoftaki, G., and Fritz, K. S. (2016). Quantification of neural ethanol and acetaldehyde using headspace GC-MS. Alcohol. Clin. Exp. Res. 40, 1825-1831. doi: 10.1111/acer.13156

Israel, Y., Quintanilla, M. E., Karahanian, E., Rivera-Meza, M., and HerreraMarschitz, M. (2015). The "first hit" toward alcohol reinforcement: role of ethanol metabolites. Alcohol. Clin. Exp. Res. 39, 776-786. doi: 10.1111/acer. 12709

Israel, Y., Rivera-Meza, M., Karahanian, E., Quintanilla, M. E., Tampier, L., Morales, P., et al. (2012). Gene specific modifications unravel ethanol and acetaldehyde actions. Front. Behav. Neurosci. 7:80. doi: 10.3389/fnbeh.2013. 00080

Jamal, M., Ameno, K., Kumihashi, M., Ameno, S., Kubota, T., Wang, W., et al. (2003). Microdialysis for the determination of acetaldehyde and ethanol concentrations in the striatum of freely moving rats. J. Chromatogr. $B$ Analyt. Technol. Biomed. Life Sci. 798, 155-158. doi: 10.1016/j.jchromb.2003. 09.015

Jamal, M., Ameno, K., Tanaka, N., Ito, A., Takakura, A., Kumihashi, M., et al. (2015). Ethanol and acetaldehyde after intraperitoneal administration to Aldh2knockout mice-reflection in blood and brain levels. Neurochem. Res. 41, 1029-1034. doi: 10.1007/s11064-015-1788-6

Jamal, M., Ameno, K., Uekita, I., Kumihashi, M., Wang, W., and Ijiri, I. (2007). Catalase mediates acetaldehyde formation in the striatum of free-moving rats. Neurotoxicology 28, 1245-1248. doi: 10.1016/j.neuro.2007.05.002

Karahanian, E., Quintanilla, M. E., Tampier, L., Rivera-Meza, M., Bustamante, D., Gonzalez-Lira, V., et al. (2011). Ethanol as a prodrug: brain metabolism of ethanol mediates its reinforcing effects. Alcohol. Clin. Exp. Res. 35, 606-612. doi: 10.1111/j.1530-0277.2011.01439.x

Kaufman, M. J., Chiu, T.-M., Mendelson, J. H., Woods, B. T., Mello, N. K., Lukas, S. E., et al. (1994). In vivo proton magnetic resonance spectroscopy of alcohol in rhesus monkey brain. Magn. Resonan. Imaging 12, 1245-1253. doi: 10.1016/0730-725X(94)90089-A

Kennedy, R. T. (2013). Emerging trends in in vivo neurochemical monitoring by microdialysis. Curr. Opin. Chem. Biol. 17, 860-867. doi: 10.1016/j.cbpa.2013.06. 012

Kerr, J. T., Maxwell, D. S., and Crabb, D. W. (1989). Immunocytochemistry of alcohol dehydrogenase in the rat central nervous system. Alcohol. Clin. Exp. Res. 13, 730-736. doi: 10.1111/j.1530-0277.1989.tb00412.x

Kotanen, C. N., Moussy, F. G., Carrara, S., and Guiseppi-Elie, A. (2012). Implantable enzyme amperometric biosensors. Biosens. Bioelectron. 35, 14-26. doi: 10.1016/j.bios.2012.03.016

Kristoffersen, L., and Smith-Kielland, A. (2005). An automated alcohol dehydrogenase method for ethanol quantification in urine and whole blood. J. Anal. Toxicol. 29, 387-389. doi: 10.1093/jat/29.5.387

Ledesma, J. C., Miquel, M., Pascual, M., Guerri, C., and Aragon, C. M. G. (2014). Induction of brain cytochrome $\mathrm{P} 4502 \mathrm{E} 1$ boosts the locomotor-stimulating effects of ethanol in mice. Neuropharmacology 85, 36-44. doi: 10.1016/j. neuropharm.2014.05.018

Lorenzo, E., Pariente, F., Hernàndez, L., Tobalina, F., Darder, M., Wu, Q., et al. (1998). Analytical strategies for amperometric biosensors based on chemically modified electrodes. Biosens. Bioelectron. 13, 319-332. doi: 10.1016/S09565663(97)00138-3

Mori, O., Haseba, T., Kameyama, K., Shimizu, H., Kudoh, M., Ohaki, O., et al. (2000). Histological distribution of class III alcohol dehydrogenase in human brain. Brain Res. 852, 186-190. doi: 10.1016/S0006-8993(99)02201-5

Nagel, B. J., and Kroenke, C. D. (2008). The use of magnetic resonance spectroscopy and magnetic resonance imaging in alcohol research. Alcohol Res. Health 31, 243-246.

Nichols, S. P., Koh, A., Storm, W. L., Shin, J. H., and Schoenfisch, M. H. (2013). Biocompatible materials for continuous glucose monitoring devices. Chem. Rev. 113, 2528-2549. doi: 10.1021/cr300387j

Niciu, M. J., and Mason, G. F. (2014). Neuroimaging in alcohol and drug dependence. Curr. Behav. Neurosci. Rep. 1, 45-54. doi: 10.1007/s40473-0130005-7
Noguer, T., and Marty, J. L. (1997). Reagentless sensors for acetaldehyde. Anal. Lett. 30, 1069-1080. doi: 10.1016/j.talanta.2008.04.040

Noguer, T., Tencaliec, A., Calas-Blanchard, C., Avramescu, A., and Marty, J.-L. (2001). Interference-free biosensor based on screen-printing technology and sol-gel immobilization for determination of acetaldehyde in wine. J. AOAC Int. $85,1382-1389$.

Olivo, J., Carrara, S., and De Micheli, G. (2011). Energy harvesting and remote powering for implantable biosensors. IEEE Sens. J. 11, 1573-1586. doi: 10.1109/ JSEN.2010.2085042

Peana, A. T., Porcheddu, V., Bennardini, F., Carta, A., Rosas, M., and Acquas, E. (2015). Role of ethanol-derived acetaldehyde in operant oral self-administration of ethanol in rats. Psychopharmacology 232, 4269-4276. doi: 10.1007/s00213015-4049-0

Pellegrino, S., Bruno, F. S., and Petrarulo, M. (1999). Liquid chromatographic determination of ethyl alcohol in body fluids. J. Chromatogr. B Biomed. Sci. Appl. 729, 103-110. doi: 10.1016/S0378-4347(99)00131-0

Peris, J., Zharikova, A., Li, Z., Lingis, M., MacNeill, M., Wu, M. T., et al. (2006). Brain ethanol levels in rats after voluntary ethanol consumption using a sweetened gelatin vehicle. Pharmacol. Biochem. Behav. 85, 562-568. doi: 10.1016/j.pbb.2006.10.010

Quintanilla, M. E., Tampier, L., Karahanian, E., Rivera-Meza, M., HerreraMarschitz, M., and Israel, Y. (2012). Reward and relapse: complete geneinduced dissociation in an animal model of alcohol dependence. Alcohol. Clin. Exp. Res. 36, 517-522. doi: 10.1111/j.1530-0277.2011.01606.x

Rooney, W. D., Lee, J. H., Li, X., Wang, G. J., Franceschi, D., Springer, C. S., et al. (2000). 4.0 T water proton T1 relaxation times in normal human brain and during acute ethanol intoxication. Alcohol. Clin. Exp. Res. 24, 830-836. doi: 10.1111/j.1530-0277.2000.tb02062.x

Rotzinger, S., Smith, B. R., and Amit, Z. (1994). Catalase inhibition attenuates the acquisition of ethanol and saccharin-quinine consumption in laboratory rats. Behav. Pharmacol. 5, 203-209. doi: 10.1097/00008877-199404000-00012

Sammi, M. K., Pan, J. W., Telang, F. W., Schuhlein, D., Molina, P. E., Volkow, N. D., et al. (2000). Measurements of human brain ethanol T2 by spectroscopic imaging at 4T. Magn. Reson. Med. 44, 35-40. doi: 10.1002/1522-2594(200007) 44:1<35::AID-MRM7<3.0.CO;2-G

Sánchez-Catalán, M. J., Hipólito, L., Guerri, C., Granero, L., and Polache, A. (2008). Distribution and differential induction of CYP2E1 by ethanol and acetone in the mesocorticolimbic system of rat. Alcohol Alcohol. 43, 401-407. doi: 10.1093/ alcalc/agn 012

Saxena, U., and Das, A. B. (2016). Nanomaterials towards fabrication of cholesterol biosensors: Key roles and design approaches. Biosens. Bioelectron. 75, 196-205. doi: 10.1016/j.bios.2015.08.042

Sirca, D., Vardeu, A., Pinna, M., Diana, M., and Enrico, P. (2014). A robust, state-of-the-art amperometric microbiosensor for glutamate detection. Biosens. Bioelectron. 61C, 526-531. doi: 10.1016/j.bios.2014.04.054

Soares, D. P., and Law, M. (2009). Magnetic resonance spectroscopy of the brain: review of metabolites and clinical applications. Clin. Radiol. 64, 12-21. doi: 10.1016/j.crad.2008.07.002

Strózik-Kotlorz, D. (2014). Magnetic resonance spectroscopy of the human brain. Phys. Part. Nuclei 45, 347-348. doi: 10.1134/S1063779614010997

Takeuchi, T., Murase, K., and Ishii, D. (1988). Determination of alcohols in alcoholic beverages by micro high-performance liquid chromatography with indirect photometric detection. J. Chromatogr. 445, 139-144. doi: 10.1016/ S0021-9673(01)84515-5

Tampier, L., Quintanilla, M. E., Karahanian, E., Rivera-Meza, M., HerreraMarschitz, M., and Israel, Y. (2013). The alcohol deprivation effect: marked inhibition by anticatalase gene administration into the ventral tegmental area in rats. Alcohol. Clin. Exp. Res. 37, 1278-1285. doi: 10.1111/acer.12101

Tampier, L., Quintanilla, M. E., and Mardones, J. (1995). Effects of aminotriazole on ethanol, water, and food intake and on brain catalase in UChA and UChB rats. Alcohol 12, 341-344. doi: 10.1016/0741-8329(95)00014-I

Thévenot, D. R., Toth, K., Durst, R. A., and Wilson, G. S. (2001). Electrochemical biosensors: recommended definitions and classification. Biosens. Bioelectron. 16, 121-131. doi: 10.1016/S0956-5663(01)00115-4

Timmerman, W., and Westerink, B. H. (1997). Brain microdialysis of GABA and glutamate: what does it signify? Synapse 27, 242-261.

Tindberg, N., and Ingelman-Sundberg, M. (1996). Expression, catalytic activity, and inducibility of cytochrome P450 2E1 (CYP2E1) in the rat central nervous 
system. J. Neurochem. 67, 2066-2073. doi: 10.1046/j.1471-4159.1996.6705 2066.x

Tiscione, N. B., Alford, I., Yeatman, D. T., and Shan, X. (2011). Ethanol analysis by headspace gas chromatography with simultaneous flame-ionization and mass spectrometry detection. J. Anal. Toxicol. 35, 501-511. doi: 10.1093/anatox/35.7. 501

Vigneshvar, S., Sudhakumari, C. C., Senthilkumaran, B., and Prakash, H. (2015). Recent advances in biosensor technology for potential applications - An overview. Front. Bioeng. Biotechnol. 4:11. doi: 10.3389/fbioe.2016.00011

Vijayakumar, A. R., Csöregi, E., Heller, A., and Gorton, L. (1996). Alcohol biosensors based on coupled oxidase-peroxidase systems. Anal. Chim. Acta 327, 223-234. doi: 10.1016/0003-2670(96)00093-1

Vogel, M., Büldt, A., and Karst, U. (2000). Hydrazine reagents as derivatizing agents in environmental analysis-a critical review. Fresenius J. Anal. Chem. 366, 781-791. doi: 10.1007/s002160051572

Wahono, N., Qin, S., Oomen, P., Cremers, T. I. F., de Vries, M. G., and Westerink, B. H. C. (2012). Evaluation of permselective membranes for optimization of intracerebral amperometric glutamate biosensors. Biosens. Bioelectron. 33, 260-266. doi: 10.1016/j.bios.2012.01.019

Wang, J., Du, H., Jiang, L., Ma, X., de Graaf, R. A., Behar, K. L., et al. (2013a). Oxidation of ethanol in the rat brain and effects associated with chronic ethanol exposure. Proc. Natl. Acad. Sci. U.S.A. 110, 14444-14449. doi: 10.1073/pnas. 1306011110

Wang, J., Du, H., Ma, X., Pittman, B., Castracane, L., Li, T.-K., et al. (2013b). Metabolic products of [2-(13) C] ethanol in the rat brain after chronic ethanol exposure. J. Neurochem. 127, 353-364. doi: 10.1111/jnc.12405

Warner, M., and Gustafsson, J. A. (1994). Effect of ethanol on cytochrome P450 in the rat brain. Proc. Natl. Acad. Sci. U.S.A. 91, 1019-1023. doi: 10.1073/pnas.91. 3.1019

Weltin, A., Kieninger, J., Enderle, B., Gellner, A.-K., Fritsch, B., and Urban, G. A. (2014). Polymer-based, flexible glutamate and lactate microsensors for in vivo applications. Biosens. Bioelectron. 61, 192-199. doi: 10.1016/j.bios.2014.05.014

Weltin, A., Kieninger, J., and Urban, G. A. (2016). Microfabricated, amperometric, enzyme-based biosensors for in vivo applications. Anal. Bioanal. Chem. 408, 4503-4521. doi: 10.1007/s00216-016-9420-4

Westerink, B. H. (1995). Brain microdialysis and its application for the study of animal behaviour. Behav. Brain Res. 70, 103-124. doi: 10.1016/0166-4328(95) 80001-8

Wilson, G. S., and Gifford, R. (2004). Biosensors for real-time in vivo measurements. Biosens. Bioelectron. 20, 2388-2403. doi: 10.1016/j.bios.2004. 12.003
Xiang, Y., and Shen, J. (2011). In vivo detection of intermediate metabolic products of [1-13C]ethanol in the brain using 13C MRS. NMR Biomed. 24, 1054-1062. doi: $10.1002 / \mathrm{nbm} .1653$

Xiao, H.-T., He, L., Tong, R.-S., Yu, J.-Y., Chen, L., Zou, J., et al. (2014). Rapid and sensitive headspace gas chromatography-mass spectrometry method for the analysis of ethanol in the whole blood. J. Clin. Lab. Anal. 28, 386-390. doi: $10.1002 /$ jcla. 21698

Yao, T., and Handa, S. (2003). Electroanalytical properties of aldehyde biosensors with a hybrid-membrane composed of an enzyme film and a redox Os-polymer film. Anal. Sci. 19, 767-770. doi: 10.2116/analsci.19.767

Yarita, T., Nakajima, R., Otsuka, S., Ihara, T. A., Takatsu, A., and Shibukawa, M. (2002). Determination of ethanol in alcoholic beverages by high-performance liquid chromatography-flame ionization detection using pure water as mobile phase. J. Chromatogr. A 976, 387-391. doi: 10.1016/S0021-9673(02)00942-1

Yoshimoto, K., and Komura, S. (1993). Monitoring of ethanol levels in the rat nucleus accumbens by brain microdialysis. Alcohol Alcohol. 28, 171-174.

Zachut, M., Shapiro, F., and Silanikove, N. (2016). Detecting ethanol and acetaldehyde by simple and ultrasensitive fluorimetric methods in compound foods. Food Chem. 201, 270-274. doi: 10.1016/j.foodchem.2016.01.079

Zahr, N. M., Mayer, D., Rohlfing, T., Hasak, M. P., Hsu, O., Vinco, S., et al. (2010). Brain injury and recovery following binge ethanol: evidence from in vivo magnetic resonance spectroscopy. Biol. Psychiatry 67, 846-854. doi: 10.1016/ j.biopsych.2009.10.028

Ziegler, T. L., Bludeau, P., Petersen, D. R., Gonzalez, F. J., and Deitrich, R. A. (2006). CYP2E1 and catalase influence ethanol sensitivity in the central nervous system. Pharmacogenet. Genomics 16, 51-58. doi: 10.1097/01.fpc.0000182777. 95555.56

Zimatkin, S. M., Pronko, S. P., Gonzalez, F. J., and Deitrich, R. A. (2006). Enzymatic mechanisms of ethanol oxidation in the brain. Alcohol. Clin. Exp. Res. 30, 1500-1505. doi: 10.1111/j.1530-0277.2006.00181.x

Conflict of Interest Statement: The authors declare that the research was conducted in the absence of any commercial or financial relationships that could be construed as a potential conflict of interest.

Copyright (c) 2017 Enrico and Diana. This is an open-access article distributed under the terms of the Creative Commons Attribution License (CC BY). The use, distribution or reproduction in other forums is permitted, provided the original author(s) or licensor are credited and that the original publication in this journal is cited, in accordance with accepted academic practice. No use, distribution or reproduction is permitted which does not comply with these terms. 